\title{
Within- and between-subjects partial reinforcement effects with an autoshaped response using Japanese quail (Coturnix coturnix japonica)
}

\author{
LAWRENCE L. CRAWFORD, JANICE N. STEIRN, and WILLIAM B. PAVLIK \\ University of Georgia, Athens, Georgia
}

\begin{abstract}
Animals exposed to schedules of partial reinforcement are typically more resistant to extinction than are animals trained with continuous reinforcement. This is the partial reinforcement effect (PRE). Animals experienced with both partial and continuous schedules are often more persistent on the continuous schedule, yielding a reversed PRE. Both conventional and reversed PREs have been elusive with classical conditioning paradigms. The present experiment attempted to demonstrate between- and within-subject PREs using 50\% and $100 \%$ autoshaping schedules. Presence or absence of a PRE depended on the behavioral measures used. Marked terminal group differences in acquisition produced a between-subjects PRE with absolute response levels but not with rate-of-change measures. Within subjects, only choice trial comparisons were sensitive enough to differentiate the two schedules. Acquisition data were inconsistent with most of the classical conditioning PRE literature, but consistent with results reported in the autoshaping literature. These discrepancies may reflect the operant-classical interaction in autoshaping.
\end{abstract}

Brown and Jenkins (1968) signaled upcoming noncontingent food presentations with a keylight and found that their pigeons pecked reliably at the key, even though responding had no scheduled effect. This training procedure, known as autoshaping, was devised originally as a method of training pigeons to keypeck, a response widely regarded (at the time) as an operant. Subsequent research has caused the autoshaped response to be regarded as largely the result of classical conditioning, with operant conditioning playing a less important role in both acquisition and maintenance (e.g., Gamzu \& Williams, 1973; Hearst \& Jenkins, 1974; Schwartz \& Williams, 1972). Since both S-S and R-S associations appear to be involved in autoshaping, and because of the long history of research in which the keypeck clearly functions as an operant, any classification of the autoshaped keypeck as either an operant or a respondent would be overly simplistic.

One phenomenon that frequently distinguishes operant conditioning from classical conditioning is the betweensubjects partial reinforcement effect in nonhumans (Kimble, 1961). The partial reinforcement effect (PRE) is a very reliable and robust phenomenon in operant conditioning situations, with subjects who have been trained

Portions of these data were presented at the annual meeting of the Eastern Psychological Association in Baltimore, April 13, 1984. L. L. Crawford is now at the Department of Psychology of Temple University. Reprint requests should be sent to W. B. Pavlik, Department of Psychology, University of Georgia, Athens, GA 30602. with intermittent schedules of reinforcement being considerably more resistant to extinction than are subjects trained with continuous reinforcement. However, the PRE is a very unreliable phenomenon in between-subjects classical conditioning experiments with nonhumans (Mackintosh, 1974). Why this difference has been the case is not clear. However, not only is the R-S contingency lacking in the classical procedure, but most instrumental PRE studies have used appetitive conditioning. The classical attempts at producing PREs typically use aversive conditioning, although there have been exceptions (Gibbon, Farrell, Locurto, Duncan, \& Terrace, 1980; Peden \& Hearst, 1977; Slivka \& Bitterman, 1966; Wagner, Siegel, Thomas, \& Ellison, 1964).

Peden and Hearst (1977) reported a significant PRE with pigeons in an autoshaping task. Their data were unusual, however, in that their partial reinforcement (PRF) group performed at a much higher level during training than did their continuous reinforcement (CRF) group-a finding opposite to that of most PRE classical conditioning studies. Gibbon et al. (1980) report similar training data. In contrast, higher levels of responding from PRF subjects are common in operant conditioning studies. One such case of higher level responding on PRF than on CRF schedules in instrumental conditioning situations has been termed the "frustration effect" (Amsel, 1958), in which responding on trials following nonreward (TFN) is higher than on trials following reward (TFR), presumably due to the energizing effects from the "frustration" experienced on nonrewarded trials. Unfortunately, Peden and Hearst (1977) did not analyze their data so as to per- 
mit any assessment of the TFR versus TFN responding in their PRF subjects. Part of the present experiment was to determine the replicability of both the higher performance in the PRF group during acquisition and the significant PRE between subjects in autoshaping. Sequential data were also collected to determine whether the higher PRF performance during acquisition could be attributed to a frustration effect.

Another purpose of the present experiment was to examine the PRE in an autoshaping situation on a withinsubjects basis. It often is the case (e.g., Pavlik \& Carlton, 1965; Pavlik \& Collier, 1977) that within-subjects comparisons yield a reversed PRE (i.e., greater resistance to extinction associated with CRF than with PRF) in both free-operant and discrete-trial operant conditioning situations. We are aware of only the two within-subjects PRE experiments in classical conditioning with nonhumans by Pavlik and Domato (1977), which both yielded significant, though small, reversed PREs. Both were done with rats and involved conditioned emotional response (CER) procedures. The current experiment pursued this topic by examining the PRE in a classical conditioning situation (autoshaping in Japanese quail) with both between-subjects and within-subjects procedures.

\section{METHOD}

\section{Subjects}

Twenty adult male Japanese quail (Coturnix coturnix japonica) were maintained at approximately $80 \%$ of their free-feeding weights for the duration of the study.

\section{Apparatus}

Two $27 \times 30.5 \times 35 \mathrm{~cm}$ aluminum and Plexiglas experimental chambers were located in a sound-attenuating room with white noise and ventilation fans masking extraneous noise. The $5 \times 5 \mathrm{~cm}$ magazine apertures were centered $2 \mathrm{~cm}$ above the floors. Each chamber also contained three response keys, $13.5 \mathrm{~cm}$ above the floor, $5.5 \mathrm{~cm}$ apart, center-to-center. All programming and data collection were performed by a SYM-1 microcomputer located in an adjoining room.

\section{Procedure}

Each subject was assigned randomly to one of three groups: eight birds to Within, six to PRF (partial), and six to CRF (continuous). Each animal was magazine trained by hand until it reliably approached and ate from the food hopper. The houselight remained lit throughout magazine training.

The experiment involved three phases during which performance of the autoshaped response was examined in both acquisition and extinction in subjects that experienced a $100 \%$ schedule of UCS delivery (Group CRF), a $50 \%$ schedule of UCS delivery (Group PRF), or both schedules (Group Within). Although the between-subjects (Group CRF vs. Group PRF) and within-subjects (Group Within) portions of the experiment were run concurrently over all three phases, they will be described separately in order to reduce confusion and redundancy.

\section{Between Subjects}

Phase 1. During autoshaping, one of two stimuli, green or a pattern (a circle for half the subjects and three parallel lines with a positive slope for the others), was presented on the center key for $7 \mathrm{sec}$. Each stimulus presentation was preceded by an 80 -sec intertrial interval (ITI). Upon termination of the stimulus, the subject either received 3-sec access to Purina Game Bird Chow fol- lowed by the ITI or immediately entered the ITI. The houselight remained on throughout the session. Responses to the center key were counted, but had no consequences. Six random stimulus sequences were generated for each group, with the restriction that no stimulus be presented more than twice in succession.

Group PRF received 12 trials per session, 6 with each stimulus. There was a $50 \%$ likelihood of food presentation at the offset of either stimulus. Group CRF also received 12 trials per session, 6 with each stimulus. All stimulus presentations, however, were followed by food delivery.

After 23 sessions of autoshaping/automaintenance training, all subjects began extinction training. Four of the six random stimulus sequences used in acquisition were used in extinction, except none of the stimuli were followed by food. Seven days of extinction testing were given to all subjects.

Phase 2. Phase 2 was conducted to obtain acquisition and extinction data from Groups CRF and PRF after Group CRF had experienced nonreinforced trials (EXT of Phase 1). Phase 2 was a replication of Phase 1 . All birds were given 15 days of reacquisition, followed by 10 days of extinction testing for Groups CRF and PRF.

Phase 3. At the end of Phase 2, there were still consistent differences in responding between Groups CRF and PRF (see below), which could have been due to an effect of the schedules of UCS presentation or to an unequal distribution of high and low responders among the two groups. To examine this question, the schedules were reversed for these two groups in Phase 3.

Group CRF was placed on a schedule of $50 \%$ UCS delivery, and the group designation became CRF/PRF to indicate this change. Group PRF was placed on a schedule of $100 \%$ UCS delivery, and the group designation was changed to PRF/CRF. During this phase, a yellow, rather than a green, stimulus was presented and the patterns were changed to a diamond in one box and three negatively sloping parallel lines in the other box. As before, both stimuli had identical probabilities of being followed by food. The same stimulus sequences were used as in Phases 1 and 2. The major difference in this third acquisition was the reversal of schedules. All subjects received 19 sessions of acquisition followed by 9 extinction sessions.

\section{Within Subjects}

Phase 1. Except as described here, the procedures for Group Within were identical to those for Groups CRF and PRF in the between-subjects design. Group Within received 24 trials per session, 12 with each stimulus. One stimulus signaled $100 \%$ food presentation at the stimulus offset. The other stimulus signaled food at the end of $50 \%$ of the stimulus presentations. Green always signaled food (CRF) for half of the Group Within subjects, and the pattern sometimes signaled food (PRF). For the remaining Within animals, green signaled PRF and pattern signaled CRF.

After 23 sessions of autoshaping/automaintenance training, Group Within subjects were given 7 days of extinction training. Four of the six random stimulus sequences used in acquisition were used in extinction, except none of the stimuli were followed by food.

Phase 2. Phase 2 was conducted to determine whether the failure to obtain a within-subjects PRE (see below) was due to insufficient training during Phase 1 . Phase 2 was a replication of Phase 1. Group Within birds were given 15 days of reacquisition, followed by 7 days of extinction testing.

Phase 3. Phase 3 tested for the apparent lack of discrimination between the two schedules by Group Within during Phases 1 and 2 (see below). This was examined by the use of "probe" trials using a choice test procedure during Phase 3 . The location of the first peck on choice trials was recorded as an additional index of discrimination.

Of the original eight subjects in Group Within, four were selected for this phase. Due to equipment restrictions, only one experimental chamber could project stimuli on two keys simultaneously. The four subjects chosen were those that had been run in this chamber 
through Phases 1 and 2. The response rates of these four animals were not systematically different from those of the four animals that were eliminated in this phase. One of the experimental chambers described in Apparatus above was used. Stimuli were projected on the side keys only; the center key remained dark throughout Phase 3.

The same stimuli and schedules were in effect as in the first two acquisition phases (green and pattern), but on 24 trials a single stimulus appeared on either the left or right key. On four choice trials (Trials 7, 14, 20, and 26), both stimuli were presented, one on the left and the other on the right key. Choice trials always terminated with food presentations during acquisition. All other aspects of the experiment remained unchanged from the first two acquisition phases. The CRF stimulus was on the left key for six single-stimulus and two choice trials and on the right for six single-stimulus and two choice trials. The same was true of the PRF stimulus. The stimulus/schedule correlation was counterbalanced across subjects. Following six sessions of acquisition, 5 days of extinction testing were given. Extinction sessions were the same as the acquisition sessions, except that no food was delivered.

\section{RESULTS}

\section{Phase 1}

\section{Between Subjects}

The upper panel of Figure 1 shows the response rates for all groups in both acquisition and extinction training. Group PRF had a significantly higher response rate than Group CRF during the final 3 days of acquisition $[F(1,10)$ $=5.66, \mathrm{p}<.05]$. (Throughout this and subsequent phases, there was a great deal of intersubject variability in response rates. This variance may have prevented some visually large differences in group means from reaching statistical significance.)

A two-way analysis of variance (ANOVA) performed on response data for Groups CRF and PRF across extinction sessions yielded a significant effect of schedule $[F(1,10)=16.02, p<.01]$ and sessions $[F(6,60)=$ $27.36, \mathrm{p}<.001]$. The schedule $\times$ sessions interaction was not statistically significant, indicating a similar course of extinction for the two groups, with Group PRF maintaining a higher rate of responding throughout extinction.

Assessing differences in extinction between groups that ended acquisition with different levels of performance is a problem of long standing. Using absolute measures of extinction performance may produce extinction differences that are simply the carryover effects of such acquisition differences. Anderson (1963) has suggested using transformed extinction data in which the transformation corrects for such acquisition differences. Given the acquisition differences between Groups CRF and PRF, Anderson (1963) ratios were calculated for each animal each day of extinction. The ratios were calculated by dividing each session's performance by the mean performance of the final 3 days of acquisition. The use of such ratios mathematically equated the groups at the end of acquisition. These ratios were then subjected to a two-way ANOVA, between groups and across sessions. With the initial difference in response rate eliminated, the significant effect of schedules disappeared and the only signifi-
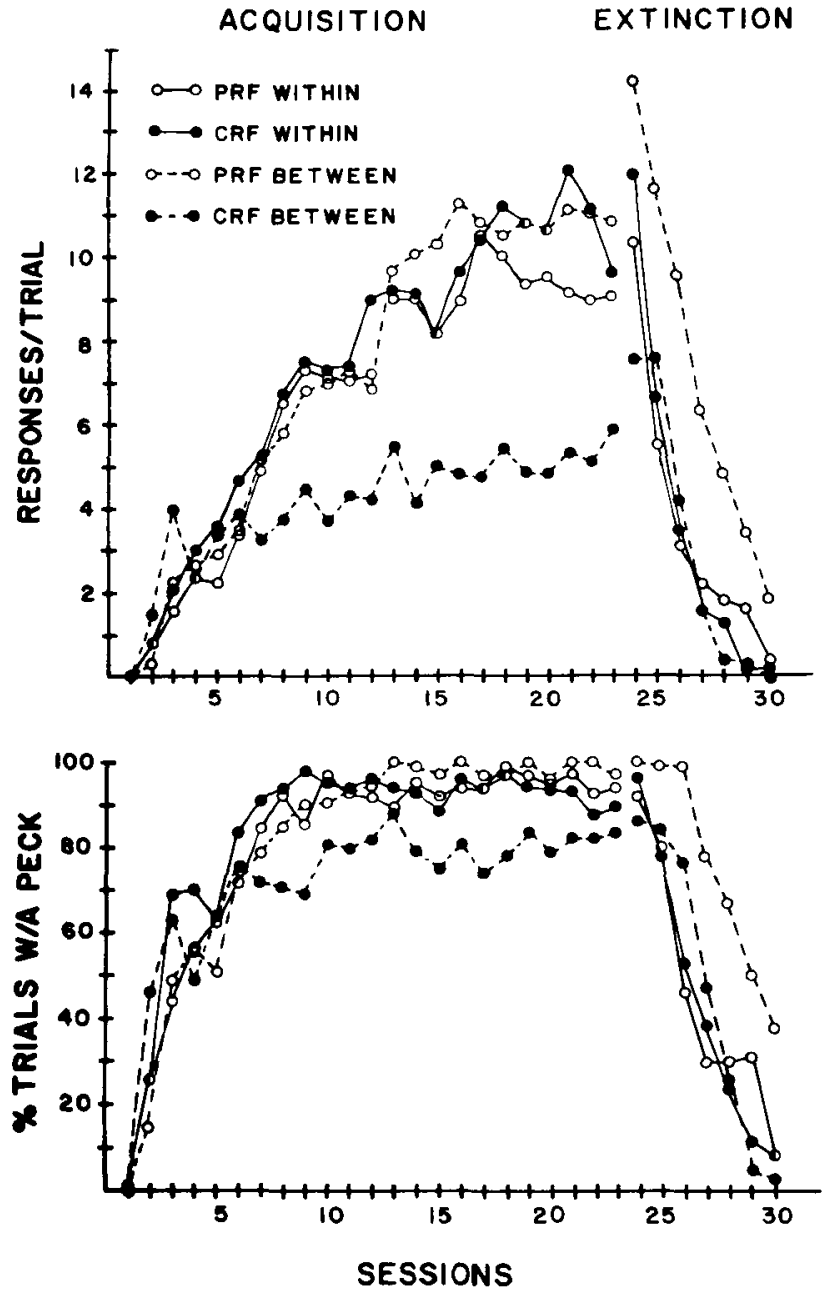

Figure 1. Phase 1 acquisition and extinction data for each group. Top panel shows mean responses per 7-sec trial. Bottom panel shows the mean percentage of trials with at least one response.

cant effect in this analysis was that of sessions $[F(6,60)$ $=15.51, \mathrm{p}<.001]$.

The number of trials in which at least one peck occurred was converted to a percentage (see Figure 1, bottom panel), and a two-way ANOVA was performed on the extinction data for Groups CRF and PRF. Group PRF had a significantly greater percentage of trials with a peck than did Group CRF $[F(1,10)=11.35, p<.01]$. The effect of sessions was also significant $[F(6,60)=26.86, p<$ $.001]$; however, the schedule $\times$ sessions interaction was not significant.

The higher response rates for Group PRF were not due to any "frustration effect" with accelerated responding on TFN compared with TFR. Mean responses per trial over the last 3 days of acquisition training were 11.1 for TFN and 10.7 for TFR.

Taken collectively, the various original and transformed measures of performance during extinction indicate that the answer to the question of whether a PRE occurs in 
between-subjects autoshaping experiments depends upon the measure used. If persistence is defined simply in terms of the number of responses elicited (or emitted) during extinction, then a conventional PRE may be said to have occurred. However, if persistence is defined in terms of relative resistance to change (e.g., Nevin, 1979), in which extinction performance is evaluated relative to acquisition asymptotes, then no PRE occurred; CRF and PRF generated equal levels of persistence.

The basis for the lower response rates for Group CRF during acquisition remains unclear. It may be noted in Figure 1 that Group CRF not only responded less than Group PRF, but also less than did Group Within on either its CRF or PRF schedule. Since Group CRF was the only group in the experiment that (during Phase 1) had not experienced any nonreinforced trials, it may be hypothesized that differences in responding during autoshaping are a function of differences in the number or proportion of nonreinforced trials. This hypothesis was the basis of Phase 2.

\section{Phase 2}

Phase 2 was conducted after Group CRF had experienced nonreinforced trials (EXT of Phase 1). The data from Phase 2 are depicted in Figure 2. Again, the response rate for Group PRF was higher than that of Group CRF during the last 3 days of acquisition $[F(1,10)$ $=5.17, \mathrm{p}<.05]$. As can be seen in the top panel of Figure 2, the response rate of Group PRF was also higher than the response rates of Group Within's two schedules.

As in Phase 1, analyses of response data in extinction yielded a significant effect of schedules between Groups CRF and PRF and a significant effect of sessions $[F(1,10)$ $=43.27, \mathrm{p}<.001 ; \mathrm{F}(9,90)=16.07, \mathrm{p}<.001$, respectively]. In Phase 2, however, the schedule $\times$ sessions interaction was significant $[\mathrm{F}(9,90)=3.96, \mathrm{p}<.01]$. An examination of the top panel of Figure 2 reveals a parallel course of extinction for Groups CRF and PRF for the first four extinction sessions. The interaction appears to be due to a basement effect. That is, Group CRF simply reached a near-zero level of responding before Group PRF, probably because of an initially lower response rate. When the ANOVA was repeated for only the first four extinction sessions, the schedule and sessions main effects remained intact $[\mathrm{F}(1,10)=42.88, \mathrm{p}<.001 ; \mathrm{F}(3,30)=$ $6.06, \mathrm{p}<.01$, respectively], but the schedule $\times$ sessions interaction no longer reached statistical significance.

Anderson ratios were again calculated using the last 3 days of Phase 2 acquisition as baseline. An analysis of these ratios showed the schedule effect to be nonsignificant, whereas the sessions effect remained significant $[\mathrm{F}(3,30)=24.75, \mathrm{p}<.001]$. The schedule $\times$ sessions interaction was significant when the first four or when all of the extinction sessions were considered $[\mathrm{F}(3,30)=$ $24.75, \mathrm{p}<.001 ; \mathrm{F}(9,90)=2.48, \mathrm{p}<.05$, respectively]. Relative to their acquisition rates, the extinction rates dropped more quickly across sessions for Group CRF than for Group PRF.
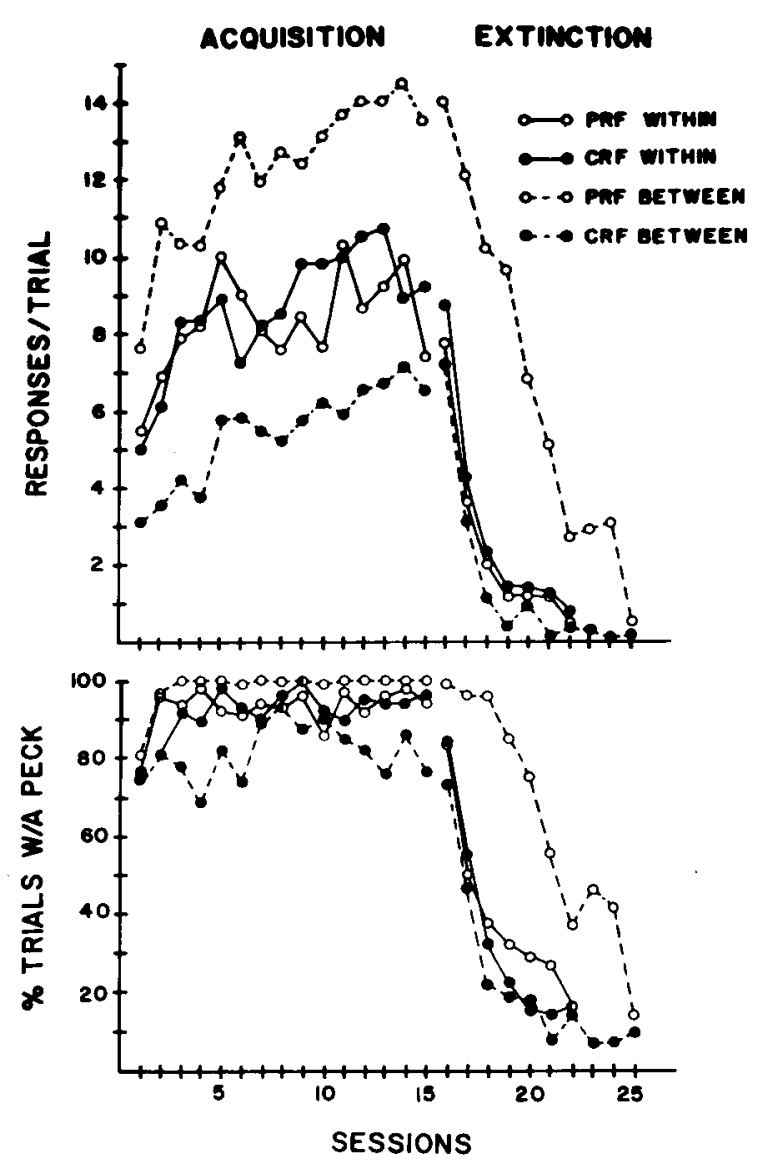

Figure 2. Phase 2 acquisition and extinction data for each group. Top panel shows the mean responses per 7-sec trial. Bottom panel shows the mean percentage of trials with at least one response.

Trials with a peck data also yielded significant effects for schedules $[\mathrm{F}(1,10)=32.42, \mathrm{p}<.001]$, sessions $[\mathrm{F}(9,90)=25.76, \mathrm{p}<.001]$, and the schedule $\times$ sessions interaction $[F(9,90)=5.12, p<.001]$ for the entire set of extinction sessions and for the first four extinction sessions $[\mathrm{Fs}=166.12,14.81$, and 7.68, respectively; $\mathrm{p}<.001$ in each case].

The pattern of results from Phase 2 differs somewhat from that of Phase 1. Group PRF continued to produce significantly more responses during acquisition/maintenance than did Group CRF (compare Figures 1 and 2). During extinction, however, a conventional PRE was obtained when either absolute or relative (to acquisition) response measures were used. Group PRF not only produced more responses during extinction, but also yielded a slower decline in Anderson ratios and in the number of trials producing at least one peck. These differences occurred mainly during the first four extinction sessions. Beyond that point, the basement effect shown by Group CRF makes meaningful comparisons difficult. Group CRF did show more rapid extinction in Phase 2 than in Phase 1 (compare Figures 1 and 2), but Group PRF did not. It should be noted that successive ac- 
quisitions and extinctions for the same subjects sometimes produce progressively faster extinction (see Mackintosh, 1974, pp. 441-442.).

The finding that the nonreinforced extinction trials experienced by Group CRF during Phase 1 did not substantially increase their level of acquisition responding relative to Group PRF during Phase 2 led to a more direct test of the hypothesis that schedule of nonreinforcements determines acquisition responding during autoshaping. This was accomplished by reversing the reinforcement schedules for Groups CRF and PRF during Phase 3.

\section{Phase 3}

The switching of reinforcement schedules for Groups CRF/PRF and PRF/CRF during Phase 3 resulted in the absence of any significant differences in level of acquisition responding, even though Group PRF/CRF did maintain a small numerical superiority in number of responses produced (see Figure 3 ). This suggests that schedule of nonreinforcements during acquisition did play some role in determining level of responding, and that the effect may be a nonreversible one (i.e., Group PRF/CRF did not show any decline in responding). During extinction, analyses of response data, Anderson ratios (relative to mean responses from the last 3 days of Phase 3 acquisition), and percent trials with a peck data failed to reveal any significant differences between the groups. Significant effects of sessions did occur with all three measures $[\mathrm{Fs}(8,80)=12.95$ for responses, 8.63 for Anderson ratios, and 24.10 for percent trials with a peck, $p<.001$ in each case], indicating simply that extinction did occur.

\section{Phase 1}

\section{Within Subjects}

As the data in Figure 1 indicate, there were no differences between schedules for Group Within. (The Group Within subjects developed a preference for the pattern stimulus, which was maintained in subsequent phases. Since the stimuli were counterbalanced across subjects, this preference did not confound the results of the study.) Thus, the results from Group Within do not indicate either a reversed or a conventional PRE. In fact, there was virtually no difference in the response rates on the two schedules. It is possible that the PRE does not develop within subjects under the conditions of this study. However, it was also possible that Group Within had not had enough experience with the two schedules to discriminate between them. Additional training, followed by extinction, was conducted in Phase 2.

\section{Phase 2}

Since the response rates for the two schedules of the Within group were not different at the end of acquisition (see Figure 2), Anderson ratios for extinction were not analyzed. An ANOVA was performed on the response data, and the schedule $\times$ sessions interaction was not found to be significant, indicating no differential effect of schedule across extinction sessions. No significant ef-
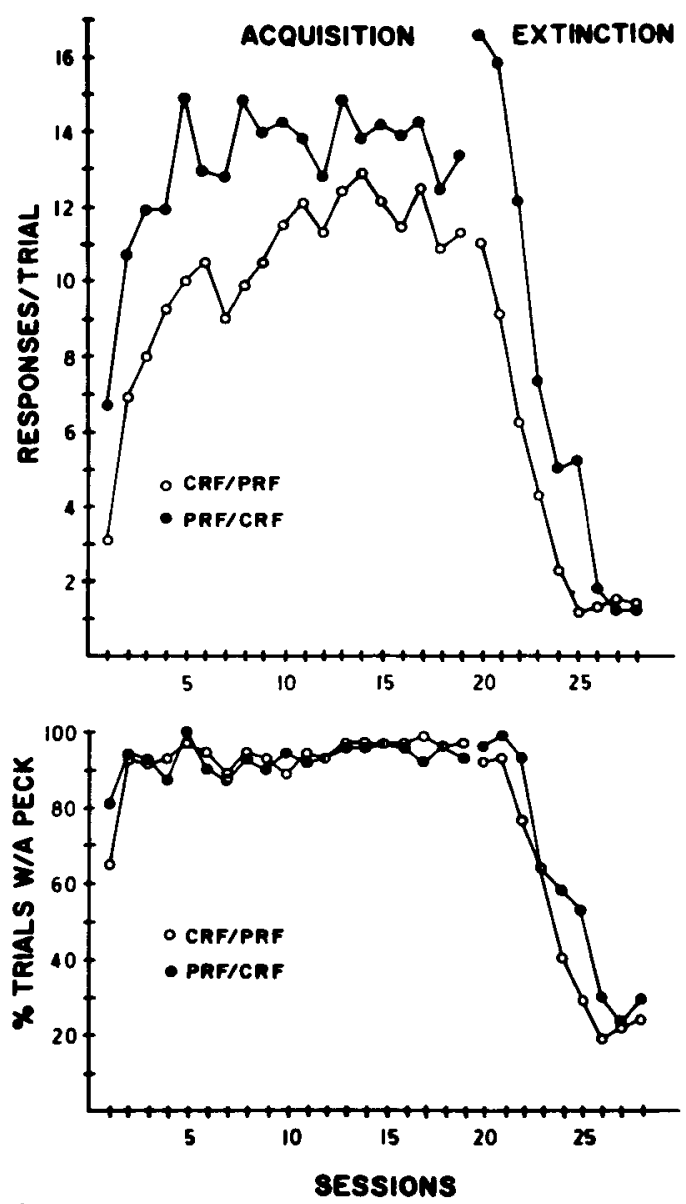

Figure 3. Phase 3 acquisition and extinction data for the betweensubjects groups. Top panel shows the mean responses per 7-sec trial. Bottom panel shows the mean percentage of trials with at least one response.

fect of schedule was found in this analysis, indicating roughly equal responding to the two schedules of CS-UCS presentation. The analysis of percent-trials-with-a-peck data also failed to find a significant schedule $\times$ sessions interaction or schedule effect. This persistent failure to find any within-subjects schedules effect is unusual (see above) and may indicate that such effects simply do not occur in autoshaping. A more parsimonious explanation, however, is that the birds simply were not discriminating the schedules. The choice trial procedures of Phase 3 were designed to answer the latter question.

\section{Phase 3}

Again, there was no PRE of any kind evident for Group Within on single-stimulus trials (see upper right panel, Figure 4). On choice trials, however, large preferences for the CRF stimulus were evident from the 1st day of the third acquisition phase (see Figure 4). These differences hold for location of first peck $[F(1,6)=49.09$, $p$ $<.001]$, percent trials with at least one peck $[\mathrm{F}(1,6)=$ $46.44, \mathrm{p}<.001]$, and percent total responses $[\mathrm{F}(1,6)=$ 

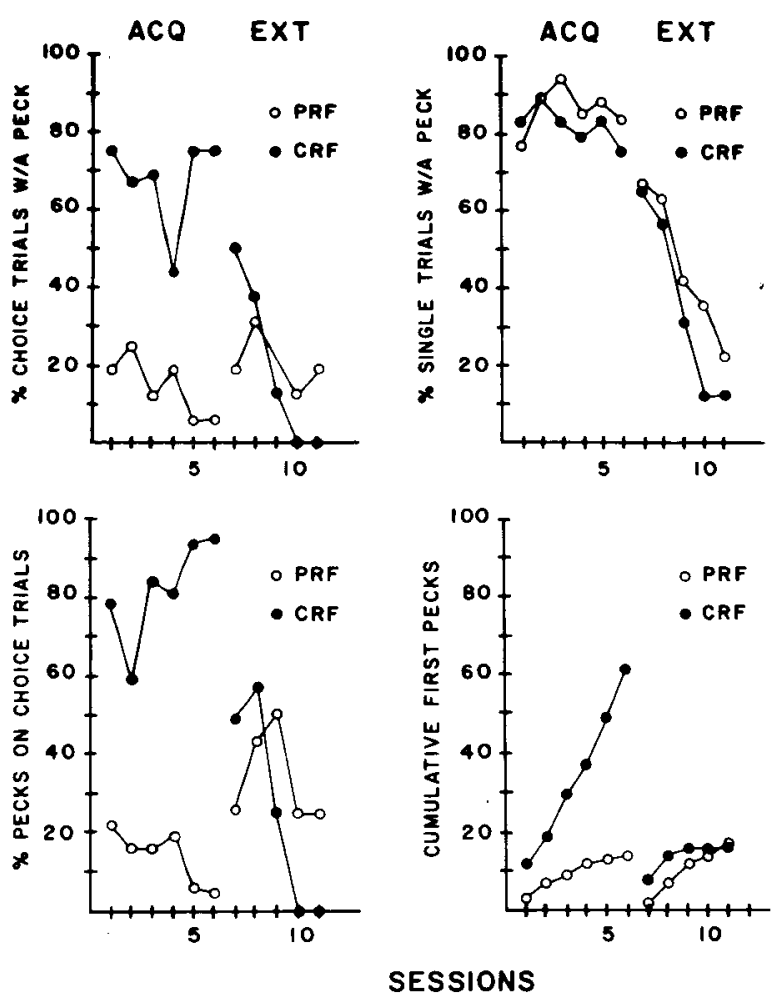

Figure 4. Phase 3 acquisition and extinction data for Group Within. The top left panel shows the percentage of choice trials with at least one response. The top right panel shows the percentage of single-stimulus trials with at least one response. The bottom left panel shows the percentage of total responses on choice trials. The bottom right panel shows the cumulative number of first pecks on choice trials.

$76.24, \mathrm{p}<.001\}$. In extinction, this preference for the CRF stimulus gave way to a preference for the PRF stimulus using the first two measures via a significant schedule $\times$ sessions interaction $[F(4,24)=3.65, \mathrm{p}<.05$, location of first peck; $F(4,24)=3.47, p<.05$, percent trials with a peck], but no significant interaction was found for percent total responses.

Collectively, the results of Phase 3 indicate that the birds were clearly discriminating the two schedules, but that such discrimination was not manifested on singlestimulus trials (i.e., discriminative performance occurred with simultaneous, but not with successive, discrimination procedures). Single-stimulus trials again yielded no evidence of either a conventional or reversed PRE. The significant schedule $\times$ sessions interactions on two choicetrial measures, however, suggest a reversed PRE early in extinction followed by a conventional PRE late in extinction.

\section{DISCUSSION}

The principal findings of the present experiment were that, in between-subjects comparisons, PRF led both to a higher level of responding during acquisition and maintenance and to higher levels of responding during extinc- tion than did CRF, but not to a slower rate of extinction than did CRF. Characterizing these between-subjects results as a PRE raises the question of how resistance to extinction is to be defined. If total responses during extinction defines persistence, then a conventional PRE may be said to have occurred; no PRE occurred, however, if rate of decline of performance is used to define persistence. In within-subjects comparisons, no differences between CRF and PRF schedules were apparent during either acquisition or extinction. The absence of withinsubjects differences, however, was not due to a failure on the part of the subjects to discriminate the schedules and their associated cues; "probe" trials during Phase 3, which required a choice between CRF and PRF cues, clearly indicated that the subjects had discriminated the schedules and preferred the CRF schedule. Furthermore, choice trials during extinction revealed a "switchover" of preference from the CRF cue early in extinction to a preference for the PRF cue late in extinction (see Figure 4). This finding may appear to suggest a greater persistence of approach to the PRF stimulus and might, therefore, be regarded as evidence for a conventional PRE. However, it might also be that preference for the PRF stimulus late in extinction on choice trials occurred simply as a consequence of the prior extinction of the initially stronger preference for the CRF stimulus. In any event, the effect (although significant) was not large (see Figure 4), and, given the single-stimulus data, it appears prudent not to conclude that a conventional within-subjects PRE occurred. It is interesting to note, however, that the conclusion drawn regarding whether a PRE occurs in such situations may well depend upon the particular response measure employed; where feasible, the use of multiple dependent variables may clarify such effects and/or prevent overly general conclusions from being drawn.

Excluding autoshaping studies, the between-subjects acquisition differences between the present CRF and PRF groups are at odds with most of the classical conditioning PRE literature using nonhumans. Typically, either no acquisition differences are found or CRF is higher than PRF performance. Most of these studies, however, used noxious UCSs (e.g., Behrend \& Bitterman, 1968; Berger, Yarczower, \& Bitterman, 1965), and the few that used appetitive UCSs (e.g., Wagner et al., 1964) did not use birds as subjects. Within the autoshaping literature, however, acquisition performance that was higher on PRF than on CRF has been found (Gibbon et al., 1980; Peden \& Hearst, 1977). (We have also obtained similar, numerically large but statistically nonsignificant, differences in pilot data with $90 \%$ PRF vs. CRF.) However, Gonzalez (1973) found no between-subjects differences in acquisition between CRF and PRF (25\%). But Gonzalez also used a complex procedure, yoked across several birds to reduce responding during the ITI, and this may have eliminated the CRF/PRF differences found here and by Gibbon et al. (1980).

Autoshaping studies that have compared within-subjects PRF and CRF schedules have reported no acquisition rate differences (Gonzalez, 1974; Perkins et al., 1975; Picker 
\& Poling, 1982). Animals given any PRF autoshape training seem to respond on all single-stimulus trials as if the entire session were one PRF schedule (i.e., they do not seem to discriminate the schedules). However, this is clearly not always the case. Birds will discriminate a $0 \%$ stimulus from a stimulus that does predict food (Perkins et al., 1975). Furthermore, Picker and Poling (1982) found that single-stimulus performance with CRF and PRF schedules did not differ even after extensive training, but their animals demonstrated a clear discrimination on choice trials. Our data are consistent with these findings and show that choice discrimination may be obtained with far less training than Picker and Poling used.

Because our experiment used both between-subjects and within-subjects CRF/PRF comparisons, we see that the within-subjects CRF response rates are elevated relative to the between-subjects CRF response rates. Furthermore, we found, in Phase 3 of the between-subjects design, that reversing the CRF and PRF schedules across groups eliminated the stable differences in response levels between the schedules during Phases 1 and 2. If this is generally the case, then exposure to nonreinforced trials during autoshaping must produce some general "arousal" or "frustration" effect which energizes responding and transcends clearly discriminable schedules. Furthermore, the fact that the analysis of our own sequential data revealed no differences in trials following food versus trials following no food suggests that such an energizing effect is more than a temporally limited carryover to the next trial.

Our extinction data from Phase 1 of the betweensubjects design may or may not be interpreted as showing a PRE, depending upon one's definition of persistence (see above). But it should be noted that they provide evidence that contradicts a conceptually appealing generalization made by Gibbon et al. (1980). In their study, several groups with different PRF schedules were employed, and Gibbon et al. suggest that the rate of decline of performance during extinction is a function of the number of expected UCSs that have not occurred. This would require that our Group PRF, which had been reinforced half the time during acquisition, show a rate of decline during extinction only half that of Group CRF. This clearly was not the case.

Finally, to return to our original question, it is clear that our findings do not point to the autoshaped response as a clear example of either an operant or a classically conditioned response. Our acquisition effects, higher levels of responding with PRF in the between-subjects design and little or no difference between schedules in the within-subjects design, clearly resemble operant and not classical conditioning findings with nonhumans. The lack of a large and clear PRE (in terms of rate of decline) in the between-subjects design resembles classical conditioning findings with nonhumans rather than operant conditioning effects. And the lack of any schedules effect during extinction in the within-subjects design resembles findings with rats in runways (e.g., Amsel, 1967) but not other operant or classical conditioning studies. Thus, the autoshaped keypeck appears (at least in the context of PREs) as if it were a hybrid response, occasionally acting like an operant and sometimes like a classically conditioned response.

\section{REFERENCES}

AMSEL, A. (1958). The role of frustrative nonreward in noncontinuous reward situations. Psychological Bulletin, 55, 102-119.

AMSEL, A. (1967). Partial reinforcement effects on vigor and persistence. In K. W. Spence \& J. T. Spence (Eds.), The psychology of learning and motivation (Vol. 1). New York: Academic Press.

ANDERSON, N. H. (1963). Comparison of different populations: Resistance to extinction and transfer. Psychological Review, 70, 162-179.

Behrend, E. R., \& Bitterman, M. E. (1968). Partial reinforcement and classical conditioning in two species of fish. Psychonomic Science, 11, 167-168.

Berger, B. D., Yarczower, M., \& Bitterman, M. E. (1965). Effect of partial reinforcement on the extinction of a classically conditioned response in the goldfish. Journal of Comparative and Physiological Psychology, 59, 399-405.

Brown, P. L., \& JENKINS, H. M. (1968). Auto-shaping of the pigeon's key-peck. Journal of the Experimental Analysis of Behavior, 11, 1-8.

GamzU, E., \& Williams, D. R. (1973). Associative factors underlying the pigeon's keypecking in auto-shaping procedures. Journal of the Experimental Analysis of Behavior, 19, 225-232.

Gibbon, J., Farrell, L., Locurto, C. M., Duncan, H. J., \& TerRACE, H. S. (1980). Partial reinforcement in autoshaping with pigeons. Animal Learning \& Behavior, 8, 45-59.

GonZaLEZ, F. A. (1973). Effects of partial reinforcement (25\%) in an autoshaping procedure. Bulletin of the Psychonomic Society, 2, 299-301.

GoNZALEZ, F. A. (1974). Effects of varying the percentage of key illuminations paired with food in a positive automaintenance procedure. Journal of the Experimental Analysis of Behavior, 22, 483-489.

HeARST, E., \& JENkINS, H. M. (1974). Sign-tracking: The stimulusreinforcer relation and directed action. Austin, TX: Psychonomic Society.

Kimble, G. A. (1961). Hilgard and Marquis' conditioning and learning. New York: Appleton-Century-Crofts.

Mackintosh, N. J. (1974). The psychology of animal learning. London: Academic Press.

Nevin, J. A. (1979). Reinforcement schedules and response strength. In M. D. Zeiler \& P. Harzem (Eds.), Reinforcement and the organization of behavior. New York: Wiley.

Pavlik, W. B., \& Carlton, P. L. (1965). A reversed partial reinforcement effect. Journal of Experimental Psychology, 70, 417-423.

PAvlik, W. B., \& Collier, A. C. (1977). Magnitude and schedule of reinforcement in rats' resistance to extinction: Within subjects. American Journal of Psychology, 90, 195-205.

Pavlik, W. B., \& Domato, G. (1977, May). Parial reinforcement effects in Pavlovian (CER) conditioning: Between and within subjects. Paper presented at the annual meeting of the Midwestern Psychological Association, Chicago.

Peden, V. R., \& Hearst, E. (1977, May). Autoshaping: The effects of partial reinforcement on the acquisition and extinction of keypecking. Paper presented at the annual meeting of the Midwestern Psychological Association, Chicago.

Perkins, C. C., Beaver, W. O., Hancock, R. A., Jr., Hemmendinger, P. C., Hemmendinger, D., \& Ricci. J. A. (1975). Some variables affecting rate of key pecking during response-independent procedures (autoshaping). Joumal of the Experimental Analysis of Behavior, 24, 59-72. 
Picker, M., \& Poling, A. (1982). Choice as a dependent measure in autoshaping: Sensitivity to frequency and duration of food presentation. Joumal of the Experimental Analysis of Behavior, 37, 393-406.

Schwartz, B., \& Williams, D. R. (1972). The role of the responsereinforcer contingency in negative automaintenance. Journal of the Experimental Analysis of Behavior, 17, 351-357.

SlivkA, R. M., \& BitTerman, M. E. (1966). Classical appetitive conditioning in the pigeon: Partial reinforcement. Psychonomic Science, 4, 181-182.
Wagner, A. R., Siegel, S., Thomas, E., \& Ellision, G. D. (1964). Reinforcement history and the extinction of a conditioned salivary response. Journal of Comparative and Physiological Psychology, 54, 354-358.

(Manuscript received June 28, 1984; revision accepted for publication October 16, 1984.)

\section{ANNOUNCEMENTS \\ 15th Annual Meeting \\ Society for Computers in Psychology}

The 15th annual meeting of the Society for Computers in Psychology will be held at the Boston Park Plaza Hotel, Boston, Massachusetts, November 21, 1985. This meeting features papers on applications of computers to all areas of psychology-experimental, clinical, and educationalwith the emphasis on on-line, laboratory applications. The deadline for papers is July 1, 1985.

For more information, contact Ira Fischler, Department of Psychology, University of Florida, Gainesville, Florida 32611 [(904)392-0605].

\section{Student Paper Competition Society for Computers in Psychology}

The Society for Computers in Psychology will continue to sponsor an award for the outstanding student paper submitted for presentation at the annual meeting. Although the primary emphasis of the conference is the use of computers in on-line, experimental applications, student papers in any area of the application of computers to psychology are welcome. Papers may be theoretical, experimental, or applied in approach. Eligibility is open to (1) work done by a student currently enrolled in undergraduate or graduate courses or (2) work done as part of a course, thesis, or other student research by a person who has graduated in 1985. All papers submitted for the conference (including multiply authored ones) in which the major contribution has been made by a student are eligible for the prize, and will be considered for presentation at the conference and subsequent publication. The winning paper will be presented at the 1985 conference, and the author will receive a complimentary 1-year membership in the conference, a complimentary 1-year subscription to Behavior Research Methods, Instruments, \& Computers, and a $\$ 50$ cash prize. Deadline for papers: July $1,1985$.

Eligible papers should be submitted in quadruplicate. A cover sheet should include the author's name, mailing address, telephone number, and academic affiliation, a 50-word abstract, and a note stating that the paper is to be considered for the student award. These materials should be sent to: Ira Fischler, Department of Psychology, University of Florida, Gainesville, FL 32611 [(904)392-0605]. 